\title{
Type 2 diabetes burden among migrants in Europe: unravelling the causal pathways
}

\author{
Charles Agyemang $^{1}$ (D) $\cdot$ Eva L. van der Linden ${ }^{1,2} \cdot$ Louise Bennet $^{3,4}$ \\ Received: 25 May 2021 / Accepted: 17 August 2021 / Published online: 16 October 2021 \\ (C) The Author(s) 2021
}

\begin{abstract}
European populations are ethnically and culturally diverse due to international migration. Evidence indicates large ethnic inequalities in the prevalence of type 2 diabetes. This review discusses the burden of type 2 diabetes and its related complications, and the potential explanatory mechanisms among migrants in Europe. The current available data suggest that the rate of type 2 diabetes is higher in all migrant groups and that they develop this disease at an earlier age than the host European populations. The level of diabetes awareness among migrant populations is high, but glycaemic control remains suboptimal compared with Europeans. The culturally adapted lifestyle modification intervention trials to prevent type 2 diabetes mainly focus on South Asian adults in Europe. Diabetes-related microvascular and macrovascular complications remain a major burden among migrant populations in Europe. Earlier studies found higher mortality rates among migrants, but recent studies seem to suggest a shifting trend in favour of first-generation migrants. However, the extent of the burden of type 2 diabetes varies across migrant groups and European countries. Despite the higher burden of type 2 diabetes among migrants, the key underlying factors are not well understood mainly due to limited investment in basic science research and development of prospective cohort studies. We hypothesise that the underlying risk factors for the high burden of type 2 diabetes and its related complications in migrants are multifaceted and include pre-migration factors, post-migration factors and genetic predispositions. Given the multi-ethnic nature of the current European population, there is a clear need for investment in research among migrant populations to gain insight into factors driving the high burden of type 2 diabetes and related complications to facilitate prevention and treatment efforts in Europe.
\end{abstract}

Keywords Ethnic minority groups $\cdot$ Europe $\cdot$ Migrants $\cdot$ Review $\cdot$ Type 2 diabetes

\section{Abbreviations \\ CHD Coronary heart disease \\ HELIUS Healthy Life in an Urban Setting \\ IFG Impaired fasting glucose}

Charles Agyemang

c.o.agyemang@amsterdamumc.nl

1 Department of Public \& Occupational Health, Amsterdam Public Health Research Institute, Amsterdam University Medical Centers, University of Amsterdam, Amsterdam, the Netherlands

2 Department of Vascular Medicine, Amsterdam Cardiovascular Sciences, Amsterdam University Medical Centers, University of Amsterdam, Amsterdam, the Netherlands

3 Department of Clinical Sciences in Malmö, Lund University, Malmö, Sweden

4 Clinical Research and Trial Centre, Lund University Hospital, Lund, Sweden
PTSD Post-traumatic stress disorder

RODAM Research on Obesity and Diabetes among African Migrants

SES Socioeconomic status

\section{Introduction}

Type 2 diabetes is one of the leading causes of cardiovascular morbidity and mortality and contributes to an increasing disease burden in all European countries [1]. Since the 1990s, the prevalence of type 2 diabetes has increased steadily in Europe, and estimates suggest that the age-adjusted prevalence rate is expected to rise from $6.3 \%$ in 2019 to $7.8 \%$ in 2045 [2]. Evidence indicates large inequalities in the rates of diabetes and related complications between migrant and ethnic minority groups (henceforth, 'migrants') and the host European-origin populations (henceforth, 'Europeans') [3]. 
Europe is ethnically diverse, especially in the urban centres, due to international migration. In the last few decades, political instability, particularly in low-resource regions of the world, has forced millions of people to seek a more stable future outside their home countries. Europe remains one of the main recipients of migrants from low-resource regions of the world, and migration is expected to increase in the coming decades [4]. To prevent early disease onset and diabetesrelated complications in migrants in Europe, special attention is needed to identify high-risk populations and the underlying determinants to guide prevention and treatment efforts. Drawing on evidence from the existing literature, this review discusses the burden of type 2 diabetes and its related complications and the potential explanatory mechanisms in migrants in Europe. The review also discusses evidence on prevention and treatment of diabetes in migrants and presents recommendations for addressing future challenges in Europe with special emphasis on migrants from low-resource countries.

\section{Migrant and host populations}

Currently, there is no universally agreed definition of what constitutes a migrant population. As a result, countries in Europe define migrants in different ways such as by nationality, country of birth and/or parental country of birth, or world region [4]. Such variations in definitions of migrants create ambiguity in comparing the health of migrants across countries. This review draws on evidence from the existing literature and we applied the various definitions used in the original studies in European countries where necessary. We used the complementary term 'host European population' to refer to people who originate from the host country. Where necessary, second-generation migrants who were born in Europe are distinguished from first-generation migrants and the host European population

\section{Type 2 diabetes burden in migrants}

The prevalence of type 2 diabetes differs importantly between ethnic groups in Europe. A meta-analysis of its prevalence among migrant groups in Europe, of papers published between 1994 and 2014, shows that generally, these groups had higher rates of type 2 diabetes compared with Europeans [3]. Migrants from South Asia had the highest rate, with the pooled OR being nearly fourfold higher, followed by those from the Middle East and North Africa, Sub-Saharan Africa and South and Central America, compared with Europeans (Fig. 1). Type 2 diabetes prevalence also differed importantly between people from a similar region of origin. For example, among the South Asian subgroups, the pooled OR of type 2 diabetes was sixfold higher in Bangladeshis, fivefold higher in Pakistanis and fourfold higher in Indians compared with Europeans [3]. The meta-analysis also shows a clear sex difference, with the magnitude of the ethnic differences in type 2 diabetes being greater in migrant women than in men, relative to Europeans [3]. Furthermore, several studies have found a higher prevalence of prediabetes or impaired fasting glucose (IFG) in several migrant groups, including migrant children, compared with Europeans [5, 6]. Middle Eastern migrants in Sweden have been shown to have higher prevalence rates of insulin resistance [7] and combined IFG\&IGT than Europeans (Fig. 2), predisposing them to a high risk of developing diabetes.
Data on intergenerational differences in type 2 diabetes prevalence among migrants are scarce but seem to suggest that the burden of diabetes cuts across different generations of migrants. A recent study among three generations of Moluccans resident in the Netherlands found higher odds of type 2 diabetes across all the three generations compared with European Dutch [8].

Evidence indicates that migrants develop type 2 diabetes 10-20 years earlier [9-11] and at a lower level of BMI [12,13] than Europeans. The United Kingdom (UK) Biobank cohort data, for example, show that, for the equivalent prevalence of diabetes at $30 \mathrm{~kg} / \mathrm{m}^{2}$ in European descent participants, BMI equated to $22.0 \mathrm{~kg} / \mathrm{m}^{2}$ in South Asians, $26.0 \mathrm{~kg} / \mathrm{m}^{2}$ in African descent populations and $24.0 \mathrm{~kg} / \mathrm{m}^{2}$ and $26.0 \mathrm{~kg} / \mathrm{m}^{2}$, respectively, in Chinese women and Chinese men [12]. Diabetes prevalence was also found to be higher in migrant children ( $<16$ years) than in European children in the UK [14]. Diabetes precursors, including $\mathrm{HbA}_{1 \mathrm{c}}$, insulin, triacylglycerol and C-reactive protein levels, have also been shown to be higher in South Asian and African-Caribbean children than in European children, even after adjusting for differences in adiposity in the UK $[15,16]$.

The prevalence of type 2 diabetes among migrants in Europe is also far higher than among the populations in their countries of origin. For instance, findings from the Research on Obesity and Diabetes among African Migrants (RODAM) study show that age- and education-adjusted prevalence of 


\section{Ethnic origin}

European

South Asian

Middle-East \& North African

Sub-Saharan African

Western Pacific

South and Central American

\section{South Asian subgroups}

Bangladeshi

Pakistani

Indian

\section{$N$}

Reference

13

8

8

3

2

3

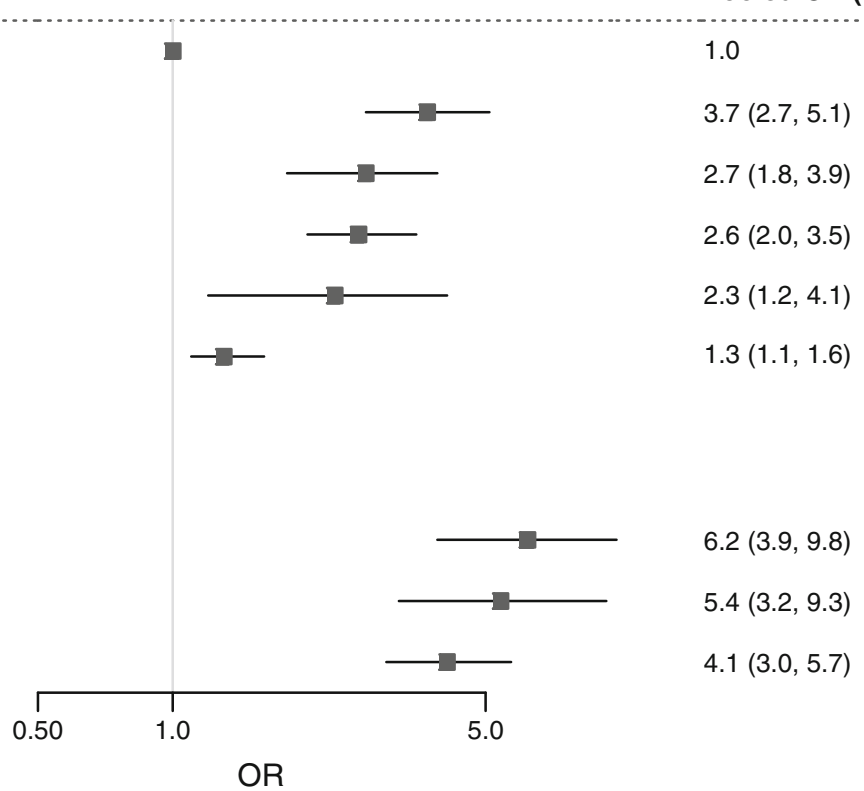

ooled OR $(95 \% \mathrm{Cl})$

$3.7(2.7,5.1)$

$2.7(1.8,3.9)$

$2.6(2.0,3.5)$

$3(1.2,4.1)$

$3(1.1,1.6)$

covering this population group. Data source: Meeks et al. [3]. This figure is available as part of a downloadable slideset

Fig. 1 Type 2 diabetes in ethnic minorities in Europe. Pooled ORs (95\% CIs) of type 2 diabetes in ethnic minorities in Europe compared with the host European population are shown. $N$ indicates the number of studies

type 2 diabetes in men ranges from threefold higher in Ghanaian migrants in London to nearly fivefold higher in Ghanaian migrants in Berlin compared with their rural Ghanaian peers [17]. In addition, Bhatnager et al. found that Punjabi people living in West London had higher fasting blood glucose than their siblings living in the Punjab [18]. Furthermore, Mbanya et al. found among populations of African descent an increased gradient of type 2 diabetes prevalence, from rural Cameroon $(0.8 \%)$ to urban Cameroon $(2.0 \%)$ through Jamaica (8.5\%) to Manchester, UK (14.6\%) [19].

\section{Diabetes-related complications in migrants}

Complications The prevalence of diabetes-related complications also differs between migrant groups and Europeans $[10,20]$. Evidence indicates a high risk of microvascular and macrovascular complications in migrants with type 2 diabetes than their European counterparts [21-23] but with great variations across migrant populations. In the recent Healthy Life in an Urban Setting (HELIUS) study, South Asian Surinamese, Moroccan and Turkish migrants had age- and sex-adjusted higher odds of nephropathy than European

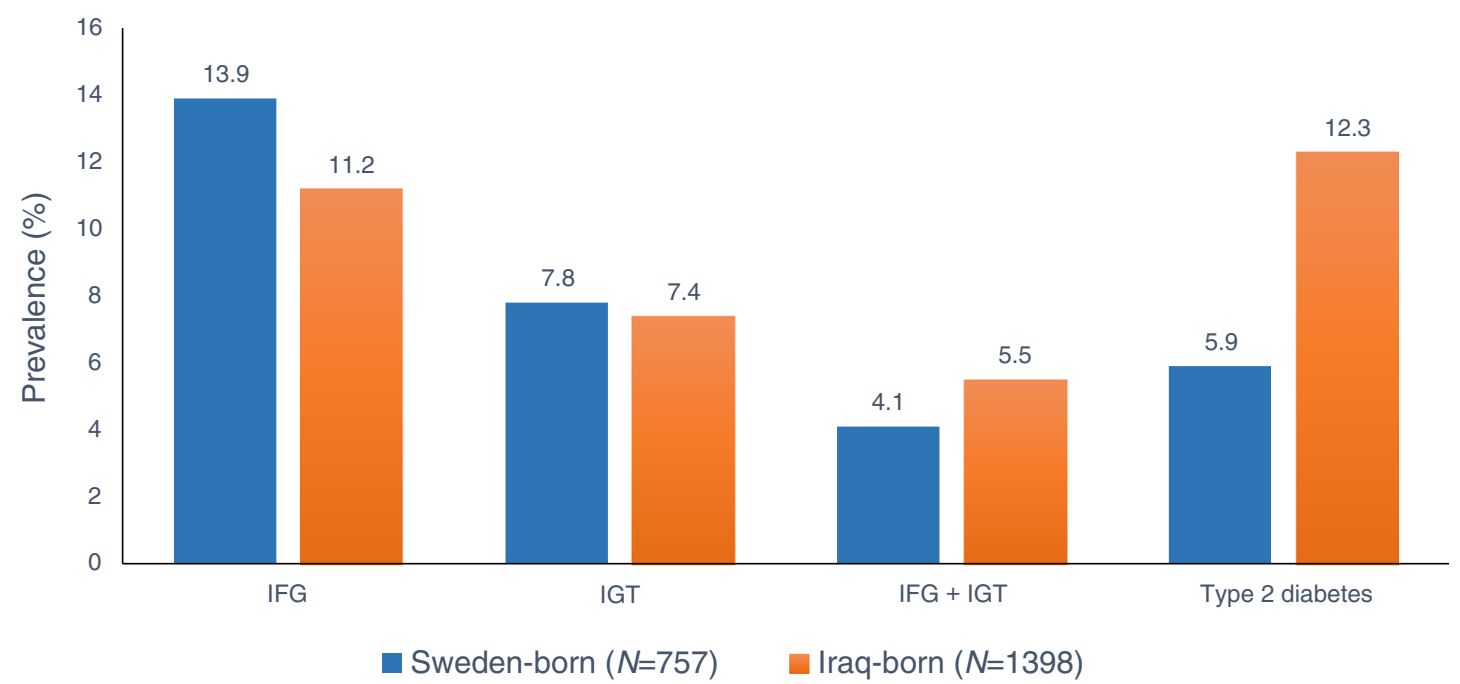

Fig. 2 Prevalence of prediabetes (IFG, IGT, or both) and type 2 diabetes in the MEDIM cohort, showing data for Middle Eastern migrants and the host European population of Swedes. Data source: Bennet et al. [7]. This figure is available as part of a downloadable slideset 
Dutch. The rate of coronary heart disease (CHD) was also higher in all migrant groups, with ORs ranging from nearly threefold higher in Ghanaian migrants to nearly sevenfold higher in Turkish migrants compared with European Dutch in the fully adjusted model [21]. In an 11-year follow-up of the Southall Diabetes Study, South Asians with type 2 diabetes were almost fourfold more likely than Europeans to report a history of myocardial infarction, but there was no significant difference in the risk of hypertension, stroke or amputation [10]. Furthermore, a 20-year follow-up of the UK-based Southall And Brent REvisited (SABRE) study showed that the risk of stroke was almost twice as high in South Asians and over twofold higher in African-Caribbean individuals with diabetes compared with their European peers [24]. A higher CHD rate was also observed in Iraqi migrants compared with Europeans in the All New Diabetics In Scania (ANDIS) study, a 10-year follow-up of individuals with new-onset type 2 diabetes in Sweden [25]. In contrast, the same study found a considerably lower incidence of chronic kidney disease in Iraqi migrants compared with European Swedes.

Mortality risk The data on ethnic differences in diabetesrelated mortality remain complex. In one study that examined differences in causes of death across different migrant groups and Europeans living in six European countries, the diabetes mortality rate ratio was higher for most migrant populations born in North Africa, Sub-Saharan Africa, the Caribbean, South Asia and Turkey but was lower for those born in East Asia and Latin America (Fig. 3) [26]. These findings corroborate those of earlier studies showing the relatively higher risk of death among migrants with type 2 diabetes compared with Europeans $[10,27]$. By contrast, more recent studies show lower mortality risks in migrants with diabetes compared with Europeans [28]. In a nationwide 10-year longitudinal study of type 2 diabetes in Sweden, the adjusted risk of all-cause mortality and cause-specific mortality (due to CVD or cancer) was lower in first-generation migrants born in the Middle East, Asia, Africa and Latin America compared with European Swedes [11]. However, second-generation migrants with type 2 diabetes, especially those with both parents born abroad, had a $28 \%$ higher risk of all-cause mortality than the European Swedes [11]. In another recent cohort study using Clinical Practice Research Datalink data from 383 general practices in England, the adjusted risks for mortality from CVD, cancer and respiratory diseases were lower in people of South Asian and African descent with diabetes compared with European with diabetes [28]. A lower risk of death has also been observed among South Asian and Chinese people with diabetes in Canada [29]. The emerging mortality advantage among migrants with type 2 diabetes is surprising and difficult to explain especially given their relatively high risk of microvascular and macrovascular complications [21-23]. It is probable that this mortality advantage may be explained, at least in part, by biological or lifestyle factors that contribute to low mortality, such as low epigenetic age acceleration [30] or beneficial effect of lifestyle intervention and medication at a young age in migrants as they appear to develop type 2 diabetes earlier than Europeans [28].

\section{Potential explanatory mechanisms for the type 2 diabetes burden in migrants}

Despite the high prevalence of diabetes and its related complications among migrants in Europe, the key underlying drivers

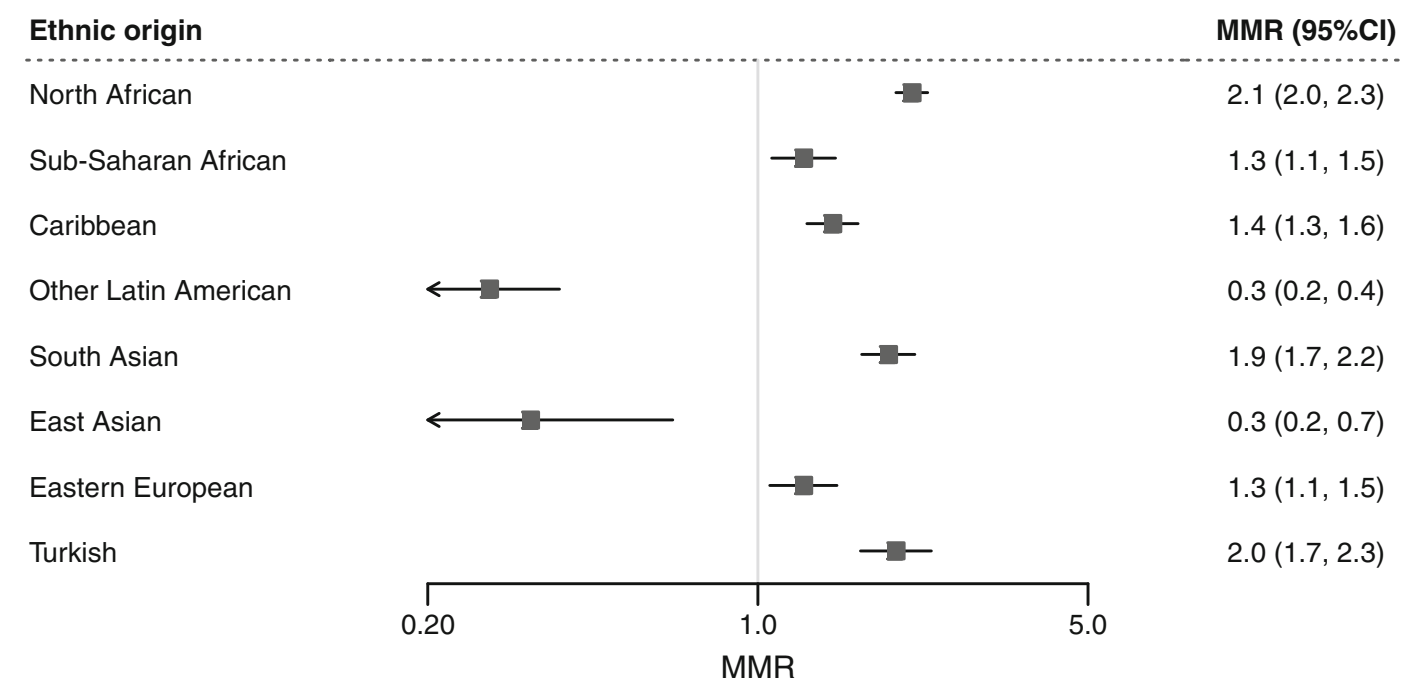

Fig. 3 Mortality rate ratios (MRRs) and 95\% CIs in diabetes-related mortality among migrant groups compared with Europeans in six European countries (Denmark, England and Wales, France, the
Netherlands, Scotland, and Spain). MRRs were adjusted for sex, age and country of destination. Data source: Ikram et al. [26]. This figure is available as part of a downloadable slideset 


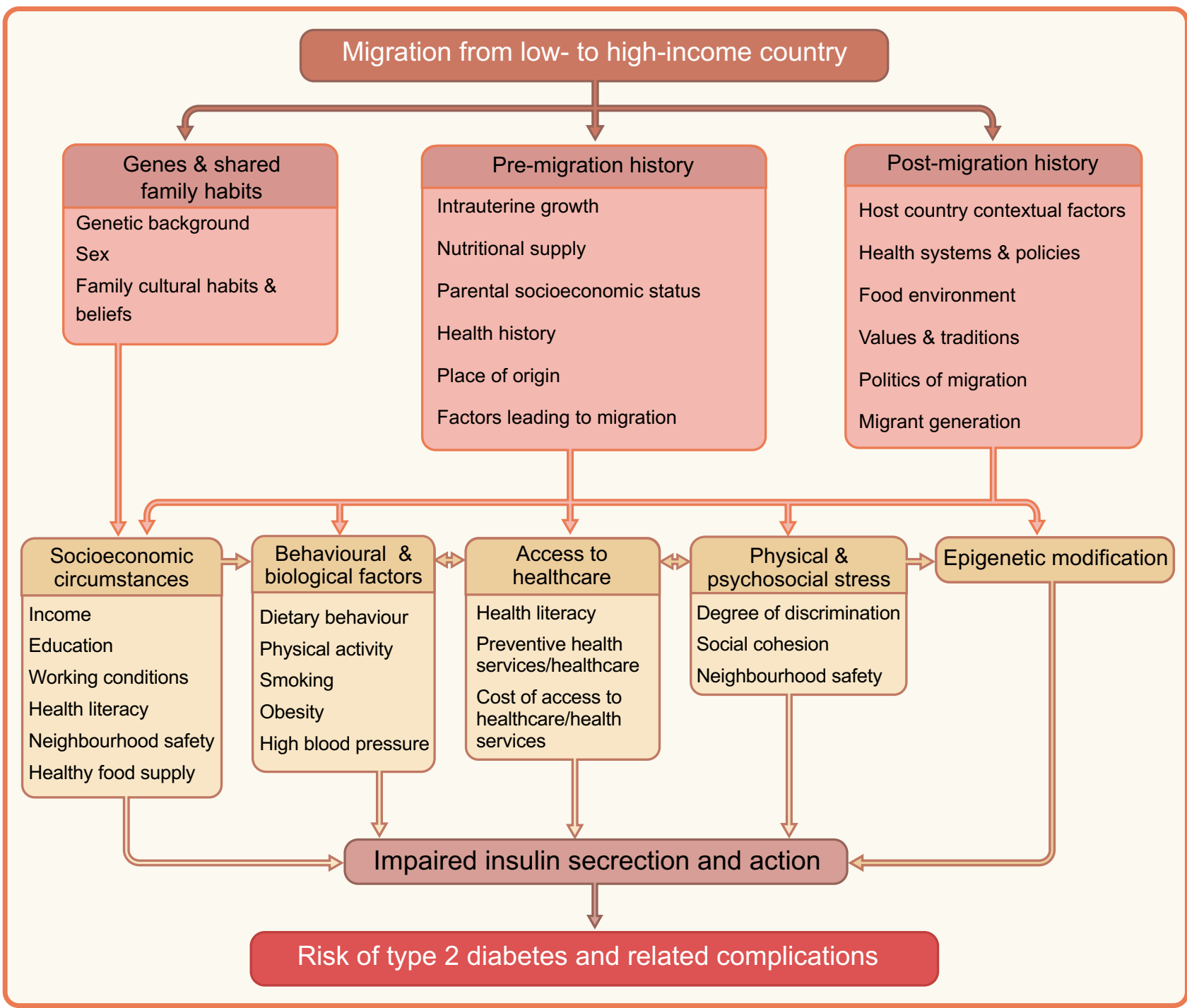

Fig. 4 Pathways leading to the high risk of type 2 diabetes in migrants. This figure is available as part of a downloadable slideset

are still not well understood. This has been mainly attributed to the inadequate investment in basic scientific research into pathophysiology and longitudinal epidemiological studies to test the relevant hypotheses in these populations. Nevertheless, it is well acknowledged that the potential factors underlying the high risk of type 2 diabetes and its related complications in migrants are multifaceted, including postmigration factors [31], pre-migration factors and genetic predispositions [32]. The conceptual model of hypothesised causal pathways leading to the high risk of type 2 diabetes in migrants is shown in Fig. 4. It is hypothesised that premigration factors (e.g. intrauterine growth, parental socioeconomic status [SES], health behaviour), post-migration factors (e.g. host countries contextual factors, health systems and policies and lifestyle changes), genetics and shared family habits can influence socioeconomic circumstances, behaviour and biological factors, access to healthcare, physical and psychosocial stress and epigenetics upon migration, which in turn affect insulin secretion and action and subsequently type 2 diabetes risk [33]. Because of the limited data on genetics and gene-environment interactions in relation to type 2 diabetes among migrants in Europe, we discuss only premigration and post-migration factors in detail.

Post-migration factors Migration is associated with huge changes in SES, lifestyle and wellbeing of migrants. One of the important changes upon migration to a new country is adjustment to the new environment. This involves changes in dietary habits, physical activity levels, psychosocial stress and socioeconomic circumstances, which are important risk factors for type 2 diabetes [33]. While migration can be beneficial in terms of improvement in SES, it can also be disastrous in terms of unhealthy lifestyle, increased psychosocial stress and limited access to preventive and curative care, with a major impact on biological factors such as obesity, IFG and subsequent type 2 diabetes [34]. 
Western diet, characterised by high consumption of red meat, processed meat, sweets, desserts and high-fat dairy products, has been shown to be associated with an increased risk of type 2 diabetes [35]. Evidence indicates changes in dietary behaviour upon migration [36, 37], which may contribute to the high prevalence of type 2 diabetes among migrants. Garduño-Diaz and Khokhar's study on the association between dietary patterns and the metabolic syndrome among South Asians living in the UK found a direct association between the western-pattern diet and the overall risk of the metabolic syndrome [36]. Furthermore, a sedentary lifestyle reduces energy expenditure, promotes weight gain and increases type 2 diabetes risk [38]. Changes in lifestyle (e.g. changes in body weight) upon migration can influence health, including type 2 diabetes. The RODAM study, which assessed African migrants living in three European countries (England, the Netherlands and Germany) and their nonmigrant compatriots living in Africa, showed that the prevalence of obesity among African (Ghanaian) migrant men in Europe was up to 15 times higher than in their compatriots living in rural Ghana [17]. The high prevalence of obesity in Ghanaian migrants was consistent with the higher prevalence of type 2 diabetes in migrants compared with their rural Ghanaian peers [17].

Migrants in European cities are frequently congregated in deprived neighbourhoods, where opportunities for social integration, as well as access to healthy food options, a safe walking environment, social support systems, healthcare providers and quality of care are often limited. This disadvantageous position makes it difficult for many migrants to engage in healthy lifestyles and can subsequently impact their health risk. White et al's natural experiment among refugees in Sweden showed that refugees who were dispersed to highly deprived neighbourhoods had a $22 \%$ higher risk of diabetes compared with refugees who were dispersed to lowdeprivation neighbourhoods [39].

Psychosocial stress and depression are associated with an increased risk of type 2 diabetes [40]. Many migrants experience discrimination, risk of deportation, separation from families, poor social circumstances including '3D' (dirty, dangerous and demeaning) jobs, poor housing, poor quality of sleep and pressure from their home countries to remit money to support those left behind; such difficulties may expose them to a high risk of psychosocial stress and depression. This, in turn, increases their risk of type 2 diabetes [41, 42]. In the HELIUS study in the Netherlands, the prevalence of self-reported perceived discrimination ranged from $28 \%$ in Ghanaian migrants to $31 \%$ in Turkish migrants, compared with $2 \%$ in European Dutch $[41,42]$. The high prevalence of perceived discrimination among these migrants groups was associated with obesity [43] and the metabolic syndrome [44], important risk factors for type 2 diabetes.
There is marked variation between host countries in terms of food environment, politics of migration, ethnic relations and organisation of healthcare and preventive services, and this can have a profound impact on the health of migrants both directly and indirectly. These differential contexts can influence migrants' health behaviour, socioeconomic circumstances, psychosocial stress and access to preventive services and healthcare and subsequent risk of diseases including type 2 diabetes [45]. Studies comparing similar South Asian Indian and African-Caribbean residents in England and the Netherlands found very important differences in obesity and type 2 diabetes among these groups living in these two countries $[45,46]$. Furthermore, the risk for type 2 diabetes is higher in women who have had gestational diabetes than in those who have not, due to defects in both insulin secretion and insulin action [47]. Evidence suggests that the prevalence of gestational diabetes is higher in most migrant groups than in Europeans, which may contribute to their high risk of type 2 diabetes [48].

Pre-migration factors Pre-migration factors may also contribute to the high prevalence of type 2 diabetes among migrants. Evidence suggests that adverse early life factors such as low birthweight and malnutrition have a profound effect on several health outcomes including type 2 diabetes in adulthood. Low childhood SES and undernutrition during early development have been shown to be associated with an increased risk of type 2 diabetes [49]. This is thought to be related to the theory of 'thrifty genotype' in which insulin resistance might improve survival rate during states of energy scarcity but would lead to type 2 diabetes in states of energy excess and the theory of 'thrifty phenotype' in which malnutrition during foetal and early life may be associated with an increased risk of insulin resistance, glucose intolerance and type 2 diabetes in adulthood [50]. Many migrants from poor-resource countries have to some extent been exposed to poor nutritional circumstances during early life, such as low birthweight, malnutrition and stunting due to poor nutrition driven by poor socioeconomic circumstances, which may expose them to high risk of type 2 diabetes upon migration to a foodabundant environment in Europe [51]. Furthermore, premigration psychosocial stress (often resulting from poverty, wars and human rights violation, which force many to flee their home countries) can have a negative impact on health, including type 2 diabetes, after migration to Europe. The migration process itself can also be treacherous, with a devastating impact on psychological wellbeing among migrants, especially among asylum seekers. According to the United Nations High Commissioner for Refugees (UNHCR), migrants routinely face horrors during their journeys such as starvation, dehydration, lack of access to medical care, arbitrary detention, kidnapping, trafficking and sexual abuse [52, 53]. The horrible experiences of some migrants en route can 
leave psychological scars and subsequently have an impact on their physical health, including type 2 diabetes, directly or indirectly through adoption of risky behaviour such as smoking, alcoholism or sedentary lifestyles as coping strategies. A study among asylum seekers in the Netherlands found that individuals with post-traumatic stress disorder (PTSD) had higher odds of diabetes than individuals without PTSD [54].

\section{Prevention and treatment of type $\mathbf{2}$ diabetes in migrants}

Prevention Though the lifetime risk of developing type 2 diabetes is high, it is difficult to predict and prevent type 2 diabetes in the general population. Nevertheless, individuals at high risk of type 2 diabetes, such as those who are obese, those with IFG or impaired glucose tolerance (IGT) and some migrant groups originating from South Asia, the Middle East and Africa, are appropriate candidates for preventive interventions [55]. Lifestyle intervention involving weight loss and increasing physical activity levels can improve insulin sensitivity and glucose tolerance and can prevent progression from IGT to type 2 diabetes [56]. However, evidence indicates that it is difficult to achieve sustained weight management with or without increased physical activity [57]. Furthermore, it has been well demonstrated that community engagement interventions have a positive effect on health behaviours, health consequences, self-efficacy and perceived social support outcomes across various health conditions [58]. However, most intervention trials have been conducted among nonmigrant populations, and it remains uncertain whether the results from these trials can be extrapolated to migrants with different lifestyle and cultural traditions. Thus, evidence on how best to deliver effective culturally adapted health promotion interventions to prevent type 2 diabetes, such as physical activity and healthy eating, to migrant groups in Europe is limited [59, 60]. In the last few years, however, culturally adapted lifestyle modification intervention trials to prevent type 2 diabetes in high-risk South Asian adults have been conducted in Norway [61], Scotland [62], the Netherlands [63] and in Iraqi migrants in Sweden [64]. The results suggest more modest effects [65] compared with trials in Europeans [66]. In addition, evidence on the clinical effectiveness or cost-effectiveness, as well as the long-term effect, of these adapted health promotion interventions among migrants in Europe is currently lacking [67]. These observations clearly demonstrate the need to identify the key facilitators and barriers for migration-related lifestyle changes, taking into account national context [68], to support cultural adaptation and evaluation of the effectiveness of these interventions among migrant groups. Moreover, other major migrant groups, such as those of African and East Asian descent, that have an increased risk of type 2 diabetes should be included in these intervention trials.

Treatment Evidence suggests that culturally appropriate education intervention can lead to improvement in glycaemic control among migrants with diabetes. A meta-analysis of 28 randomised controlled trials, including four studies in South Asians from the UK and one study from the Netherlands, on culturally appropriate diabetes health education interventions showed significant improvements in glycaemic control and diabetes knowledge over a period of 24 months among the intervention group compared with those receiving usual care [60]. However, evidence suggests that there is poor glycaemic control among migrant groups in Europe despite their high levels of diabetes awareness and treatment [69-71]. In one Dutch study, the awareness and medical treatment of type 2 diabetes were two to five times higher in migrants than in European Dutch individuals, although levels of awareness/ treatment in those with glycaemic control $\left(\mathrm{HbA}_{1 \mathrm{c}}\right.$ levels on target $\leq 52 \mathrm{mmol} / \mathrm{mol}$ ) ranged from 37 to $53 \%$ in migrant men compared with $67 \%$ in European Dutch men [9]. A study in Scotland also found higher rate of suboptimal glycaemic control in migrants compared with European Scots despite migrants being generally younger and having lower BMI [72]. The poor glycaemic control among migrants has been suggested to be due to poor adherence to treatment and lifestyle recommendations, possibly due to low health literacy, poor care standards, poor quality of care or ineffective response to glucose-lowering agents [9]. Furthermore, a large proportion of individuals who migrate from the Middle East and South Asia to Europe have insulin-deficient diabetes, which may also contribute to their poor diabetes control [13, 25]. These observations suggest the need for greater efforts to improve the effectiveness of type 2 diabetes treatment in migrant groups in Europe, taking into account the migrants' personal perspectives on diabetes. This is highly relevant because a systematic review of various ethnic minority patients' views on self-management of type 2 diabetes identified several analytical themes that highlight the complex nature of self-management of type 2 diabetes among these populations [73]. How patients identified themselves and the feeling of being understood by health professionals about their culture and by family members regarding their condition were of great importance to successful self-management, while patients' own limited understanding of diabetes was a barrier to self-management of their condition [73].

\section{Conclusions and recommendations}

Type 2 diabetes and related microvascular and macrovascular complications remain a major burden among migrant populations in Europe. However, the extent of the burden varies 
across migrant groups and the countries in which they now live. Earlier studies found higher mortality rates among migrants, but recent studies seem to suggest a shifting trends in favour of migrants. Explanations for the high risk of type 2 diabetes among migrants in Europe are mainly speculative. Evaluation of diabetes interventions among migrants are limited and mainly focus on South Asian populations. The level of awareness of diabetes among migrant populations is high, but glycaemic control remains suboptimal relative to Europeans. These observations call for investment in prospective studies and basic scientific research to gain insight into the causal pathways linking migration to the development of type 2 diabetes. The research should include the role of genetics, epigenetics, early life factors, key specific migration-related lifestyle changes and psychosocial stressors. There is also a need for intervention trials of longer duration to investigate clinical outcome measures such as development of microvascular and macrovascular complications and to evaluate the cost-effectiveness of the adapted interventions. The current data on the culturally adapted lifestyle modification intervention trials to prevent type 2 diabetes are mainly based on South Asian adults in Europe, suggesting the need for more work among other major migrant groups such as AfricanCaribbeans, Sub-Saharan Africans, North Africans, East Asian and Middle Eastern populations, such as Turkish and Iraqi populations, in whom type 2 diabetes is also highly prevalent. Lastly, in order to improve type 2 diabetes treatment outcomes among migrant groups in Europe, more work is needed to gain better understanding of factors driving the poor treatment outcomes and to help develop cultural tailored interventions for migrants with type 2 diabetes.

Supplementary Information The online version contains a slideset of the figures for download, which is available to authorised users, available at https://doi.org/10.1007/s00125-021-05586-1.

Funding $\mathrm{CA}$ is supported by the European Research Council Consolidation (grant no. 772244). LB is supported by the Swedish Research Council (Linné grant to LUDC 349-2006-237, Exodiab 2009-1039), Swedish Foundation Strategic Research Dnr IRC15-0068).

Authors' relationships and activities The authors declare that there are no relationships or activities that might bias, or be perceived to bias, their work.

Contribution statement All authors were responsible for drafting the article and revising it critically for important intellectual content. All authors approved the version to be published.

Open Access This article is licensed under a Creative Commons Attribution 4.0 International License, which permits use, sharing, adaptation, distribution and reproduction in any medium or format, as long as you give appropriate credit to the original author(s) and the source, provide a link to the Creative Commons licence, and indicate if changes were made. The images or other third party material in this article are included in the article's Creative Commons licence, unless indicated otherwise in a credit line to the material. If material is not included in the article's Creative Commons licence and your intended use is not permitted by statutory regulation or exceeds the permitted use, you will need to obtain permission directly from the copyright holder. To view a copy of this licence, visit http://creativecommons.org/licenses/by/4.0/.

\section{References}

1. Andersson E, Persson S, Hallen N et al (2020) Costs of diabetes complications: hospital-based care and absence from work for 392, 200 people with type 2 diabetes and matched control participants in Sweden. Diabetologia 63(12):2582-2594. https://doi.org/10.1007/ s00125-020-05277-3

2. International Diabetes Federation (2019) IDF Diabetes Atlas: Ninth edition 2019. Available from https://diabetesatlas.org/upload/ resources/material/20200302_133351_IDFATLAS9e-final-web. pdf. Accessed May 8th 2021

3. Meeks KA, Freitas-Da-Silva D, Adeyemo A et al (2016) Disparities in type 2 diabetes prevalence among ethnic minority groups resident in Europe: a systematic review and meta-analysis. Intern Emerg Med 11(3):327-340. https://doi.org/10.1007/s11739-0151302-9

4. International Organization for Migration (2010) World Migration Report 2010. The Future of Migration: Building Capacities for Change. Available from https://publications.iom.int/system/files/ pdf/wmr_2010_english.pdf. Accessed 8 May 2021

5. Webb DR, Gray LJ, Khunti K et al (2011) Screening for diabetes using an oral glucose tolerance test within a western multi-ethnic population identifies modifiable cardiovascular risk: the ADDITION-Leicester study. Diabetologia 54(9):2237-2246. https://doi.org/10.1007/s00125-011-2189-2

6. Hulman A, Simmons RK, Brunner EJ et al (2017) Trajectories of glycaemia, insulin sensitivity and insulin secretion in south Asian and white individuals before diagnosis of type 2 diabetes: a longitudinal analysis from the Whitehall II cohort study. Diabetologia 60(7):1252-1260. https://doi.org/10.1007/s00125-017-4275-6

7. Bennet L, Groop L, Franks PW (2014) Ethnic differences in the contribution of insulin action and secretion to type 2 diabetes in immigrants from the Middle East compared to native swedes. Diabetes Res Clin Pract 105(1):79-87. https://doi.org/10.1016/j. diabres.2014.04.025

8. Bodewes A, Agyemang C, Kunst AE (2021) Do diabetes mellitus differences exist within generations? Three generations of moluccans in the Netherlands. Int J Environ Res Public Health 18(2). https://doi.org/10.3390/ijerph18020493

9. Snijder MB, Agyemang C, Peters RJ, Stronks K, Ujcic-Voortman JK, van Valkengoed IG (2017) Case finding and medical treatment of type 2 diabetes among different ethnic minority groups: the HELIUS study. J Diabetes Res 2017:9896849. https://doi.org/10. $1155 / 2017 / 9896849$

10. Mather HM, Chaturvedi N, Fuller JH (1998) Mortality and morbidity from diabetes in south Asians and Europeans: 11-year follow-up of the Southall diabetes survey, London, UK. Diabet Med 15(1): 53-59. https://doi.org/10.1002/(SICI)1096-9136(199801)15: $1<53:$ :AID-DIA521>3.0.CO;2-V

11. Bennet L, Udumyan R, Ostgren CJ, Rolandsson O, Jansson SPO, Wandell P (2021) Mortality in first- and second-generation immigrants to Sweden diagnosed with type 2 diabetes: a 10 year nationwide cohort study. Diabetologia 64(1):95-108. https://doi.org/10. 1007/s00125-020-05279-1

12. Ntuk UE, Gill JM, Mackay DF, Sattar N, Pell JP (2014) Ethnicspecific obesity cutoffs for diabetes risk: cross-sectional study of 
490,288 UK biobank participants. Diabetes Care 37(9):2500-2507. https://doi.org/10.2337/dc13-2966

13. Sattar N, Gill JM (2015) Type 2 diabetes in migrant south Asians: mechanisms, mitigation, and management. Lancet Diabetes Endocrinol 3(12):1004-1016. https://doi.org/10.1016/S22138587(15)00326-5

14. Khanolkar AR, Amin R, Taylor-Robinson D, Viner R, Warner J, Stephenson T (2016) Ethnic minorities are at greater risk for childhood-onset type 2 diabetes and poorer glycemic control in England and Wales. J Adolesc Health 59(3):354-361. https://doi. org/10.1016/j.jadohealth.2016.05.012

15. Whincup PH, Nightingale CM, Owen CG et al (2010) Early emergence of ethnic differences in type 2 diabetes precursors in the UK: the child heart and health study in England (CHASE study). PLoS Med 7(4):e1000263. https://doi.org/10.1371/journal.pmed. 1000263

16. Harding S, Silva MJ, Molaodi OR et al (2016) Longitudinal study of cardiometabolic risk from early adolescence to early adulthood in an ethnically diverse cohort. BMJ Open 6(12):e013221. https://doi. org/10.1136/bmjopen-2016-013221

17. Agyemang C, Meeks K, Beune E et al (2016) Obesity and type 2 diabetes in sub-Saharan Africans - is the burden in today's Africa similar to African migrants in Europe? The RODAM study. BMC Med 14(1):166. https://doi.org/10.1186/s12916-016-0709-0

18. Bhatnagar D, Anand IS, Durrington PN et al (1995) Coronary risk factors in people from the Indian subcontinent living in West London and their siblings in India. Lancet 345(8947):405-409. https://doi.org/10.1016/s0140-6736(95)90398-4

19. Mbanya JC, Cruickshank JK, Forrester T et al (1999) Standardized comparison of glucose intolerance in west African-origin populations of rural and urban Cameroon, Jamaica, and Caribbean migrants to Britain. Diabetes Care 22(3):434-440. https://doi.org/ 10.2337/diacare.22.3.434

20. Vandenheede H, Deboosere P, Stirbu I et al (2012) Migrant mortality from diabetes mellitus across Europe: the importance of socioeconomic change. Eur J Epidemiol 27(2):109-117. https://doi.org/ 10.1007/s10654-011-9638-6

21. Armengol GD, Hayfron-Benjamin CF, van den Born BH, Galenkamp H, Agyemang C (2021) Microvascular and macrovascular complications in type 2 diabetes in a multi-ethnic population based in Amsterdam. The HELIUS study. Prim Care Diabetes 15(3):528-534. https://doi.org/10.1016/j.pcd.2021.02. 008

22. Davis TM, Coleman RL, Holman RR, UKPDS Group (2014) Ethnicity and long-term vascular outcomes in type 2 diabetes: a prospective observational study (UKPDS 83). Diabet Med 31(2): 200-207. https://doi.org/10.1111/dme.12353

23. Sivaprasad S, Gupta B, Gulliford MC et al (2012) Ethnic variations in the prevalence of diabetic retinopathy in people with diabetes attending screening in the United Kingdom (DRIVE UK). PLoS One 7(3):e32182. https://doi.org/10.1371/journal.pone.0032182

24. Tillin T, Hughes AD, Mayet J et al (2013) The relationship between metabolic risk factors and incident cardiovascular disease in Europeans, south Asians, and African Caribbeans: SABRE (Southall and Brent Revisited) - a prospective population-based study. J Am Coll Cardiol 61(17):1777-1786. https://doi.org/10. 1016/j.jacc.2012.12.046

25. Bennet L, Nilsson C, Mansour-Aly D, Christensson A, Groop L, Ahlqvist E (2021) Adult-onset diabetes in middle eastern immigrants to Sweden: novel subgroups and diabetic complications-the all new diabetes in Scania cohort diabetic complications and ethnicity. Diabetes Metab Res Rev 37(6):e3419. https://doi.org/10.1002/ dmrr.3419

26. Ikram UZ, Mackenbach JP, Harding S et al (2016) All-cause and cause-specific mortality of different migrant populations in Europe.
Eur J Epidemiol 31(7):655-665. https://doi.org/10.1007/s10654015-0083-9

27. Chaturvedi N, Fuller JH (1996) Ethnic differences in mortality from cardiovascular disease in the UK: do they persist in people with diabetes? J Epidemiol Community Health 50(2):137-139. https:// doi.org/10.1136/jech.50.2.137

28. Wright AK, Kontopantelis E, Emsley R et al (2017) Life expectancy and cause-specific mortality in type 2 diabetes: a populationbased cohort study quantifying relationships in ethnic subgroups. Diabetes Care 40(3):338-345. https://doi.org/10.2337/dc16-1616

29. Shah BR, Victor JC, Chiu M et al (2013) Cardiovascular complications and mortality after diabetes diagnosis for south Asian and Chinese patients: a population-based cohort study. Diabetes Care 36(9):2670-2676. https://doi.org/10.2337/dc12-2105

30. Chilunga FP, Henneman P, Elliott HR et al (2021) Epigenetic-age acceleration in the emerging burden of cardiometabolic diseases among migrant and non-migrant African populations: a population-based cross-sectional RODAM substudy. Lancet Healthy Longevity 2(6):E327-E339. https://doi.org/10.1016/ S2666-7568(21)00087-8

31. Wemrell M, Bennet L, Merlo J (2019) Understanding the complexity of socioeconomic disparities in type 2 diabetes risk: a study of 4.3 million people in Sweden. BMJ open diabetes res. Care 7(1): e000749. https://doi.org/10.1136/bmjdrc-2019-000749

32. Agyemang C (2019) Comfy zone hypotheses in migrant health research: time for a paradigm shift. Public Health 172:108-115. https://doi.org/10.1016/j.puhe.2019.03.025

33. Agyemang C, Beune E, Meeks K et al (2017) Innovative ways of studying the effect of migration on obesity and diabetes beyond the common designs: lessons from the RODAM study. Ann N Y Acad Sci 1391(1):54-70. https://doi.org/10.1111/nyas.13204

34. Helmrich SP, Ragland DR, Leung RW, Paffenbarger RS Jr (1991) Physical activity and reduced occurrence of non-insulin-dependent diabetes mellitus. N Engl J Med 325(3):147-152. https://doi.org/ 10.1056/NEJM199107183250302

35. The InterAct Consortium, Bendinelli B, Palli D et al (2013) Association between dietary meat consumption and incident type 2 diabetes: the EPIC-InterAct study. Diabetologia 56(1):47-59. https://doi.org/10.1007/s00125-012-2718-7

36. Garduño-Diaz SD, Khokhar S (2013) South Asian dietary patterns and their association with risk factors for the metabolic syndrome. J Hum Nutr Diet 26(2):145-155. https://doi.org/10.1111/j.1365277X.2012.01284.x

37. Sharma S, Cruickshank JK (2001) Cultural differences in assessing dietary intake and providing relevant dietary information to British African-Caribbean populations. J Hum Nutr Diet 14(6):449-456. https://doi.org/10.1046/j.1365-277x.2001.00319.x

38. Lao XQ, Deng HB, Liu X et al (2019) Increased leisure-time physical activity associated with lower onset of diabetes in 44828 adults with impaired fasting glucose: a population-based prospective cohort study. Br J Sports Med 53(14):895-900. https://doi.org/10. 1136/bjsports-2017-098199

39. White JS, Hamad R, Li X et al (2016) Long-term effects of neighbourhood deprivation on diabetes risk: quasi-experimental evidence from a refugee dispersal policy in Sweden. Lancet Diabetes Endocrinol 4(6):517-524. https://doi.org/10.1016/ S2213-8587(16)30009-2

40. Graham EA, Deschenes SS, Khalil MN, Danna S, Filion KB, Schmitz N (2020) Measures of depression and risk of type 2 diabetes: a systematic review and meta-analysis. J Affect Disord 265: 224-232. https://doi.org/10.1016/j.jad.2020.01.053

41. Lindert J, Ehrenstein OS, Priebe S, Mielck A, Brahler E (2009) Depression and anxiety in labor migrants and refugees-a systematic review and meta-analysis. Soc Sci Med 69(2):246-257. https://doi. org/10.1016/j.socscimed.2009.04.032 
42. Ikram UZ, Snijder MB, Fassaert TJ, Schene AH, Kunst AE, Stronks K (2015) The contribution of perceived ethnic discrimination to the prevalence of depression. Eur J Pub Health 25(2):243248. https://doi.org/10.1093/eurpub/cku180

43. Schmengler H, Ikram UZ, Snijder MB, Kunst AE, Agyemang C (2017) Association of perceived ethnic discrimination with general and abdominal obesity in ethnic minority groups: the HELIUS study. J Epidemiol Community Health 71(5):453-460. https://doi. org/10.1136/jech-2016-207875

44. Ikram UZ, Snijder MB, Agyemang C et al (2017) Perceived ethnic discrimination and the metabolic syndrome in ethnic minority groups: the healthy life in an urban setting study. Psychosom Med 79(1):101-111. https://doi.org/10.1097/PSY.0000000000000350

45. Agyemang C, Kunst AE, Bhopal R et al (2011) Diabetes prevalence in populations of south Asian Indian and African origins: a comparison of England and the Netherlands. Epidemiology 22(4):563567. https://doi.org/10.1097/EDE.0b013e31821d1096

46. Agyemang C, Kunst A, Bhopal R et al (2011) Dutch versus English advantage in the epidemic of central and generalised obesity is not shared by ethnic minority groups: comparative secondary analysis of cross-sectional data. Int J Obes 35(10):1334-1346. https://doi. org/10.1038/ijo.2010.281

47. Vounzoulaki E, Khunti K, Abner SC, Tan BK, Davies MJ, Gillies CL (2020) Progression to type 2 diabetes in women with a known history of gestational diabetes: systematic review and meta-analysis. BMJ 369:m1361. https://doi.org/10.1136/bmj.m1361

48. Dornhorst A, Paterson CM, Nicholls JS et al (1992) High prevalence of gestational diabetes in women from ethnic minority groups. Diabet Med 9(9):820-825. https://doi.org/10.1111/j.1464-5491. 1992.tb01900.x

49. Weitzman S, Wang CH, Pankow JS, Schmidt MI, Brancati FL (2010) Are measures of height and leg length related to incident diabetes mellitus? The ARIC (atherosclerosis risk in communities) study. Acta Diabetol 47(3):237-242. https://doi.org/10.1007/ s00592-009-0145-0

50. Rich-Edwards JW, Colditz GA, Stampfer MJ et al (1999) Birthweight and the risk for type 2 diabetes mellitus in adult women. Ann Intern Med 130(4 Pt 1):278-284. https://doi.org/10. 7326/0003-4819-130-4 part 1-199902160-00005

51. Bijker R, Agyemang C (2016) The influence of early-life conditions on cardiovascular disease later in life among ethnic minority populations: a systematic review. Intern Emerg Med 11(3):341353. https://doi.org/10.1007/s11739-015-1272-y

52. UNHCR (2021) The High Commissioner's IASC Championship on Protection from Sexual Exploitation and Abuse and Sexual Harassment. Available from https://www.unhcr.org/the-highcommissioners-iasc-championship-on-protection-from-sexualexploitation.html. Accessed 12th March 2021

53. The High Commissioner's IASC Championship on Protection from Sexual Exploitation and Abuse and Sexual Harassment, PSEA Community Outreach and Communication Fund (2021) Our fight against sexual exploitation, abuse and harassment. Available from https://www.unhcr.org/our-fight-against-sexual-exploitationabuse-and-harassment.html, Accessed 12 March 2021

54. Agyemang C, Goosen S, Anujuo K, Ogedegbe G (2012) Relationship between post-traumatic stress disorder and diabetes among 105,180 asylum seekers in the Netherlands. Eur J Pub Health 22(5):658-662. https://doi.org/10.1093/eurpub/ckr138

55. Brancati FL, Kao WH, Folsom AR, Watson RL, Szklo M (2000) Incident type 2 diabetes mellitus in African American and white adults: the atherosclerosis risk in communities study. JAMA 283(17):2253-2259. https://doi.org/10.1001/jama.283.17.2253

56. Balk EM, Earley A, Raman G, Avendano EA, Pittas AG, Remington PL (2015) Combined diet and physical activity promotion programs to prevent type 2 diabetes among persons at increased risk: a systematic review for the community preventive services task force. Ann Intern Med 163(6):437-451. https://doi. org/10.7326/M15-0452

57. Lemmens VE, Oenema A, Klepp KI, Henriksen HB, Brug J (2008) A systematic review of the evidence regarding efficacy of obesity prevention interventions among adults. Obes Rev 9(5):446-455. https://doi.org/10.1111/j.1467-789X.2008.00468.x

58. O'Mara-Eves A, Brunton G, McDaid D et al (2013) Community engagement to reduce inequalities in health: a systematic review, meta-analysis and economic analysis. NIHR Journals Library, Southampton

59. Liu J, Davidson E, Bhopal R et al (2012) Adapting health promotion interventions to meet the needs of ethnic minority groups: mixed-methods evidence synthesis. Health Technol Assess 16(44):1-469. https://doi.org/10.3310/hta16440

60. Creamer J, Attridge M, Ramsden M, Cannings-John R, Hawthorne K (2016) Culturally appropriate health education for type 2 diabetes in ethnic minority groups: an updated Cochrane review of randomized controlled trials. Diabet Med 33(2):169-183. https://doi.org/ 10.1111/dme.12865

61. Telle-Hjellset V, Raberg Kjollesdal MK, Bjorge B et al (2013) The InnvaDiab-DE-PLAN study: a randomised controlled trial with a culturally adapted education programme improved the risk profile for type 2 diabetes in Pakistani immigrant women. Br J Nutr 109(3): 529-538. https://doi.org/10.1017/S000711451200133X

62. Bhopal RS, Douglas A, Wallia S et al (2014) Effect of a lifestyle intervention on weight change in south Asian individuals in the UK at high risk of type 2 diabetes: a family-cluster randomised controlled trial. Lancet Diabetes Endocrinol 2(3):218-227. https:// doi.org/10.1016/S2213-8587(13)70204-3

63. Admiraal WM, Vlaar EM, Nierkens V et al (2013) Intensive lifestyle intervention in general practice to prevent type 2 diabetes among 18 to 60 -year-old south Asians: 1-year effects on the weight status and metabolic profile of participants in a randomized controlled trial. PLoS One 8(7):e68605. https://doi.org/10.1371/ journal.pone.0068605

64. Siddiqui F, Kurbasic A, Lindblad U, Nilsson PM, Bennet L (2017) Effects of a culturally adapted lifestyle intervention on cardiometabolic outcomes: a randomized controlled trial in Iraqi immigrants to Sweden at high risk for type 2 diabetes. Metabolism 66:113. https://doi.org/10.1016/j.metabol.2016.10.001

65. Tuomilehto J, Lindstrom J, Eriksson JG et al (2001) Prevention of type 2 diabetes mellitus by changes in lifestyle among subjects with impaired glucose tolerance. N Engl J Med 344(18):1343-1350. https://doi.org/10.1056/NEJM200105033441801

66. Gillett M, Royle P, Snaith A et al (2012) Non-pharmacological interventions to reduce the risk of diabetes in people with impaired glucose regulation: a systematic review and economic evaluation. Health Technol Assess 16(33):1-236, iii-iv. https://doi.org/10. 3310/hta16330

67. Lagisetty PA, Priyadarshini S, Terrell S et al (2017) Culturally targeted strategies for diabetes prevention in minority population. Diabetes Educ 43(1):54-77. https://doi.org/10.1177/ 0145721716683811

68. Olaya-Contreras P, Balcker-Lundgren K, Siddiqui F, Bennet L (2019) Perceptions, experiences and barriers to lifestyle modifications in first-generation middle eastern immigrants to Sweden: a qualitative study. BMJ Open 9(10):e028076. https://doi.org/10. 1136/bmjopen-2018-028076

69. Mukhopadhyay B, Forouhi NG, Fisher BM, Kesson CM, Sattar N (2006) A comparison of glycaemic and metabolic control over time among south Asian and European patients with type 2 diabetes: results from follow-up in a routine diabetes clinic. Diabet Med 23(1):94-98. https://doi.org/10.1111/j.1464-5491.2005.01735.x

70. Rawshani A, Svensson AM, Rosengren A, Zethelius B, Eliasson B, Gudbjornsdottir S (2015) Impact of ethnicity on progress of glycaemic control in 131,935 newly diagnosed patients with type 
2 diabetes: a nationwide observational study from the Swedish National Diabetes Register. BMJ Open 5(6):e007599. https://doi. org/10.1136/bmjopen-2015-007599

71. Tran AT, Diep LM, Cooper JG et al (2010) Quality of care for patients with type 2 diabetes in general practice according to patients' ethnic background: a cross-sectional study from Oslo, Norway. BMC Health Serv Res 10:145. https://doi.org/10.1186/ 1472-6963-10-145

72. Negandhi PH, Ghouri N, Colhoun HM et al (2013) Ethnic differences in glycaemic control in people with type 2 diabetes mellitus living in Scotland. PLoS One 8(12):e83292. https://doi.org/10. 1371/journal.pone.0083292

73. Majeed-Ariss R, Jackson C, Knapp P, Cheater FM (2015) A systematic review of research into black and ethnic minority patients' views on self-management of type 2 diabetes. Health Expect 18(5):625-642. https://doi.org/10.1111/hex.12080

Publisher's note Springer Nature remains neutral with regard to jurisdictional claims in published maps and institutional affiliations. 